\title{
Transcription of Insulin-like Growth Factor Receptor in Russian Sturgeon (Acipenser gueldenstaedtii) Ovary during Oogenesis
}

\author{
Gad Degani $^{1,2, *}$, S. Yom Din ${ }^{1,2}$, Avshalom Hurvitz ${ }^{3}$ \\ ${ }^{1}$ MIGAL - Galilee Research Institute, Kiryat Shmona, Israel \\ ${ }^{2}$ Faculty of Science and Technology, Tel-Hai Academic College, Israel \\ ${ }^{3}$ Dan Fish Farms, Israel
}

Copyright $\bigcirc 2017$ by authors, all rights reserved. Authors agree that this article remains permanently open access under the terms of the Creative Commons Attribution License 4.0 International License

\begin{abstract}
In the present study, we examined the insulin-like growth factor receptor 1(IGF-1R) transcription using real-time PCR at different stages of oocytes of Russian sturgeon (Acipenser gueldenstaedtii) at age 8-9 years and weight $25 \mathrm{~kg}$ that were grown under aquaculture conditions. Compare to the pre-vitellogenesis stage, the transcription of IGF-1R increased at the vitellogenesis stages (yellow, gray and black). The mRNA of IGF-1R of oocytes in the black stage is significantly higher than in the gray or yellow stages. However, there are no significant differences between the gray or yellow stages of the mRNA level. Based on previous studies and the result of the mRNA of IGF-1R of oocytes during oogenesis, we proposed a model for the effect of $\mathrm{GH}$, IGF-1 and IGF-1R on the oogenesis of Russian sturgeon, which is a very important process for creating caviar.
\end{abstract}

Keywords Acipenser, Insulin-like Growth Factor, mRNA, Russian Sturgeon, Receptor

\section{Introduction}

Russian sturgeon (Acipenser gueldenstaedtii) belongs to one of the most ancient groups of osteichthyes. $A$. gueldenstaedtii belong to the Osteichthyes class, Acrinopteygii sub-class, Acipenseriformes order and Acipenseridae family (Vlasenko et al.[20]). The distribution of this osteichthyes group is along the coasts of the Atlantic and Pacific Oceans, in the Mediterranean and Black Seas, and in many rivers, lakes and inland seas (Dettlaff et al.[5]). The decline of sturgeon populations in their native habitats, mainly in the Caspian Sea, is due to overfishing for meat and caviar production. This has led to the destruction of their spawning grounds and water pollution, as well as bringing about their introduction into aquaculture.

Since their roe is a source of caviar, sturgeon has a high economic value, which has become the primary factor for their exceedingly endangered status due to overfishing (Birstein et al.[1]). The growth rate of Russian sturgeon is affected by various parameters, e.g., water quality, food, the postnasal of growth and gender. In the Dan Fish Farms (Upper Galilee, Israel; $31^{\circ} 30^{\prime} \mathrm{N}, 34^{\circ} 45^{\prime} \mathrm{E}$ ), the males and females grow at the same rate during the first two years and reach a weight of about $3 \mathrm{~kg}$. After four years, the weights of the males are about $5.2 \mathrm{~kg}$ and those of the females are higher, around $6.8 \mathrm{~kg}$. In males, spermatogenesis started after two years, while in females, oogenesis starts at the age six years and reaches maturity at around seven years (Hurvitz et al. [7]; Hurvitz et al. [8]; Jackson et al. [6]).

In vertebrates, growth hormone $(\mathrm{GH})$ is a pituitary hormone that controls somatic growth (Perez-Sanchez[16]). It is a single-chain polypeptide having two intramolecular disulfide bonds. The major mediator of GH function is IGF-I, which is related structurally to insulin and similarly contains three intramolecular disulfide bonds (Moriyama et al., 2000). In seeking genetic factors affecting growth rate, $\mathrm{GH}$ is naturally considered a primary candidate. $\mathrm{GH}$ has been studied extensively in vertebrates, and the cDNA nucleotide sequences of the $\mathrm{GH}$ of many fishes are available (Degani et al.[4]; Degani et al.[3]; Yom Din et al.[24]). The complete amino-acid (aa) sequence of GH from a chondrostean species, Acipenser gueldenstaedtii, has been determined. Two variants of $\mathrm{GH}$, termed GH I and GH II, have been isolated from the pituitary. The identity of the aa sequences for both variants of the gene is $97 \%$, and they differ from each other at only three positions. Both GH consist of 190 aa residues and contain two disulfide bonds at positions 56-167 and 184-192. A sequence comparison among the $\mathrm{GH}$ of other vertebrates has revealed that sturgeon $\mathrm{GH}$ have a greater sequence homology to tetrapod $\mathrm{GH}(63-76 \%)$ than to teleost $\mathrm{GH}$ (42-63\%) (Yom Din et al.[24]).

During the first five years of growth there is no difference between females and males in the transcription of $\mathrm{GH}$. 
Pituitary adenylate cyclase-activating polypeptide (PACAP) and GH-releasing hormone (GHRH) control GH in fish and are involved in oogenesis (Lubzensa et al.[13]; Levy and Degani[10]; Lokman et al.[12]).

The mean IGF-I expression in females was studied in the brain, liver, ovary and muscle of male blue gourami (Trichogaster trichopterus) (Degani[2]), and the mRNA level in the various tissues was described.

The effect of IGF-1 was not accompanied by obvious ultrastructural changes in the oocytes other than an apparent increase in nuclear size. Similarly, treatment with recombinant human IGF-I resulted in increased oocyte diameters, whereas no such effect was seen after treatment with heterologous insulin, $\mathrm{GH}$, leptin, or human chorionic gonadotropin (Lubzensa et al.[13]). There are two forms of fish ovary development in teleostei: synchrony ovary, where all the oocytes develop together; and asynchrony ovary, where the oocytes in the ovary are found at different stages of development at the same time (Scott[18]). The ovary of the Acipenseriformes order belongs to the synchrony group, whereby a group of oocytes was found at various stages of development in the ovary (Van Eenennaam and Doroshov[19]). Two groups of oocytes were found in the ovary of Russian sturgeon: the first is primary oocytes and the second is oocytes at different stages of vitellogenesis (Hurvitz et al.[8]; Jackson et al.[6]). During the first year of maturation where the fish were at the age of 7 or 8 years, the oocytes in the ovary were found in the synchronic stage (Stage 4) (diameter 1.6-2.6 mm). When the oocytes reached the gray stage above this stage (Stage 5) (Hurvitz et al.[8]), all the oocytes reached this stage and developed together to the black stage (diameter 3-3.5 mm).

Sadler et al.[17] found hormone-responsive IGF-1 receptors in Xenopus laevis ovarian follicle cells and demonstrated that follicle cells somehow support IGF-1-stimulated oocyte maturation. Wuertz et al.[21] suggest that IGF-1 in snake (Acipenser ruthenus) function is conserved across major taxonomic groups, as well as playing novel and intriguing roles for IGF-1 in the regulation of reproductive activities among other functions such as acting as a growth factor in various tissues. Yom Din et al.[24] and Farmer et al.[6] found IGF-I mRNA expression in various tissues, whereby the level in each tissue was similar in 1-and 5-yr-old Russian sturgeon.

The aim of the present study is to examine the relationship between oocytes development in Russian sturgeon ovary and IGF-1 receptor (IGF-1R).

\section{Materials and Methods}

\section{Fish and Sampling Procedure}

Russian sturgeon was approved by the government since it would add to our knowledge about caviar production. Fertilized eggs of Russian sturgeon (A. gueldenstaedtii) originating in the Caspian Sea were brought from Russia and reared in the Dan Fish Farms (Upper Galilee, Israel; 31 ${ }^{\circ} 30^{\prime}$ $\mathrm{N}, 34^{\circ} 45^{\prime}$ E) under aquaculture conditions, as previously described by Hurvitz et al.[8]. Fish $\left(30 / \mathrm{kg} \mathrm{m}^{3}\right)$ were maintained in $250 \mathrm{~m}^{3}$ ponds made of concrete at a water temperature of $18^{\circ} \mathrm{C}$ and $12 \mathrm{~h}$ photoperiod. The oxygen concentration was $6 \mathrm{ppm}$ and controlled by oxygen analyzer (Oxygen Mater, Plaris 1 Dissolved Oxygen Mater, Petair Aquatic Eco-Systems). The ammonia and nitrite were below $0.5 \mathrm{ppm}$, and the fish were fed twice a day with $1 \%$ body weight of dry commercial feed ( $48 \%$ protein and $18 \%$ fat).

\section{Animals and Sampling}

Gonad of female Russian sturgeon at age 8-9 years and weight $25 \mathrm{~kg}$, were sampled at different stages of oogenesis. Each fish was marked individually by color and numbered with plastic cow ear-tags (Hagarin, Israel) attached to one of its pectoral fins. Each fish was anesthetized in a clove oil bath $(0.25 \mathrm{mg} / \mathrm{l})$ and placed in a V-shaped base for examination, as described previously by Hurvitz et al.[8], and oogenesis was examined using an endoscope system. The gonadal biopsy was performed using a metal trocar with a $3 \times 30 \mathrm{~mm}$ groove inserted into the ovary through the same incision used for the endoscopy. Approximately $270 \mathrm{mg}$ of tissue was collected by this method from each fish sampled. One 5 to $10 \mathrm{~mm}$ incision was made with a sterile scalpel in the abdominal wall through which the cystoscope sheath was inserted. The samples were stored in RNA Later buffer (Ambion Inc., Austin, TX). The gonads were removed, weighed and sampled for histology. Total RNA was extracted from RNA Later preserved tissues by means of the RNeasy ${ }^{\circledR}$ Total RNA Kit (QIAGEN, Alameda, CA) according to the manufacturer's recommendations. First-strand cDNA was synthesized from $2 \mu \mathrm{g}$ of total RNA by the Superscript System (Invitrogen, Carlsbad, CA).The single-strand cDNA was used to amplify a cDNA internal fragment using gene-specific primers (Table 1) (Degani[2]).

\section{Real-time PCR}

In order to compare the mRNA levels of IGF-1R measured, the real-time PCR method was used with various specific primers (Table 1) for the genes of IGF-1R. The PCR reaction of the gene IGF-1R (three replications) was done in $17 \mu \mathrm{l}$ water, $2.5 \mathrm{mix}$, with 1.5 of each primer (reverse at 10 $\mathrm{pmol} / \mu \mathrm{l}$ and forward at $20 \mathrm{pmol} / \mu \mathrm{l})$ and $5 \mu \mathrm{cDNA}$ in a dilution of 1:5 (Degani[2]).

Relative abundance was normalized with an endogenous reference, the rRNA of the $18 \mathrm{~S}$ subunit, using the comparative threshold cycle (CT) method (Muller et al. [15]).

This method was validated using serial dilutions of cDNA. The amplification efficiencies of each target mRNA and $18 \mathrm{~S}$ rRNA was compared by plotting $\Delta \mathrm{CT}$ versus $\log$ (template) 
according to the method by Muller et al.[15].

In order to evaluate the mRNA level of IGF-1R in various samples compared to the mRNA of the $18 \mathrm{~S}$ gene, the method described previously in detail by Livak and Schmittgen [11] was used. We found two results in the first evolution of $18 \mathrm{~S}$ and the cDNA of Russian sturgeon cDNA according to the methods used; therefore we designed the primer 18ST (Table 1) to normalize the mRNA of IGF-1R. The mRNA transcription IGF-1R and 18ST were studied using cDNA of amplification in various dilutions $(1: 1,1: 4,1: 16,1: 64$, 1:256), as was described previously by Muller et al.[15]. The results of real-time PCR were analyzed by the Q-Gene program.

\section{Statistical Analysis}

Data are presented as the mean \pm SEM. The significance of the differences between group means of mRNA levels was determined by one-way analysis of variance (ANOVA) followed by the chi-square test analysis, with the level of significance in different groups set at $\mathrm{p}<0.05$.

\section{Results}

The different stages of oogenesis of female Russian sturgeon are presented in Figure 1.

In the pre-vitellogenesis stage, the transcription of IGF-1R was lower compared to the vitellogenesis of various stages (yellow, gray and black). The mRNA of IGF-1R of oocytes in the black stage is significantly higher than the gray or yellow stages (Fig. 2) (ANOVA and $\mathrm{X}^{2}$ test, $\mathrm{P}<0.05$ ). However, there are no significant differences between the gray or yellow stages $\left(\mathrm{X}^{2}\right.$ test, $\left.\mathrm{P}>0.05\right)$.

\section{Discussion}

In teleost, as in other vertebrates, the hormone control growth and reproduction are associated with interaction with the hypothalamus-pituitary axis. The economic importance of Russian sturgeon affects various studies regarding both hormone control growth and reproduction. (Hurvitz et al. [8]). However, the gonadotropin axis (Yom-Din et al.[23]) is studied much more intensively in Russian sturgeon than the somatic path (Yom Din et al.[24]) as in many other fish species (Yaron and Levavi-Sivan[22]). In the present study, mRNA of IGF-1R was found to increase dramatically in the ovary during vitellogenesis compared to the pre-vitellogenesis stages. Moreover, the highest transcription of IGF-1R was found in the black stage of oocytes, the late stage of oogenesis, compared to the gray or yellow stages, the beginning of vitellogenesis. Comparing previtellogenic follicles in females that matured within two years with non-maturing females of the same age in Acipenser ruthenus, an increase of 2.3-fold for IGF-I and 2.8-fold for IGF-IR mRNA expression in maturing females was found by (Wuertz et al.[21]). The results of the present study, together with previous studies on the somatic axis of Russian sturgeon, including GH and IGF mRNA gene expression (Yom Din et al.[24]), support the idea that this axis are involved in oogenesis. These interactions along the gonadotropin and somatic axes are found not only in primitive teleosts like Russian sturgeon but also in other teleosts (Degani et al.[3]; Degani[2]; Degani et al.[4]; Levy and Degani[10]). We proposed model for the effect of GH, IGF-1 and IGF-1R involved in the gonad development of Russian sturgeon represented in Fig.3.

Table 1. Primers used in this study.

\begin{tabular}{|c|c|c|c|c|}
\hline Fish@Gene & & Primers & $\begin{array}{l}\text { Position in } \\
\text { sequence }\end{array}$ & Product size \\
\hline $\begin{array}{l}\text { Acipenser } \\
\text { IGF1Receptor }\end{array}$ & $\begin{array}{l}\text { ARexpfor2 } \\
\text { ARexprev3 }\end{array}$ & $\begin{array}{l}\text { 5' GCATCGAGTTCCTGAACGA 3' } \\
\text { 5' AGCGAGCGTAGGTAGCTCTT 3' }\end{array}$ & $\begin{array}{c}33-51 \\
183-164\end{array}$ & 153 \\
\hline Acipenser $18 \mathrm{St}$ & $\begin{array}{l}\text { Ac18Sfort } \\
\text { Ac18Srevt }\end{array}$ & $\begin{array}{l}\text { GCGAAAGCATTTGCCAAGAAT } \\
\text { GCCCTTCCGTCAATTCCTTT }\end{array}$ & $\begin{array}{c}939 \\
1159\end{array}$ & 220 \\
\hline
\end{tabular}




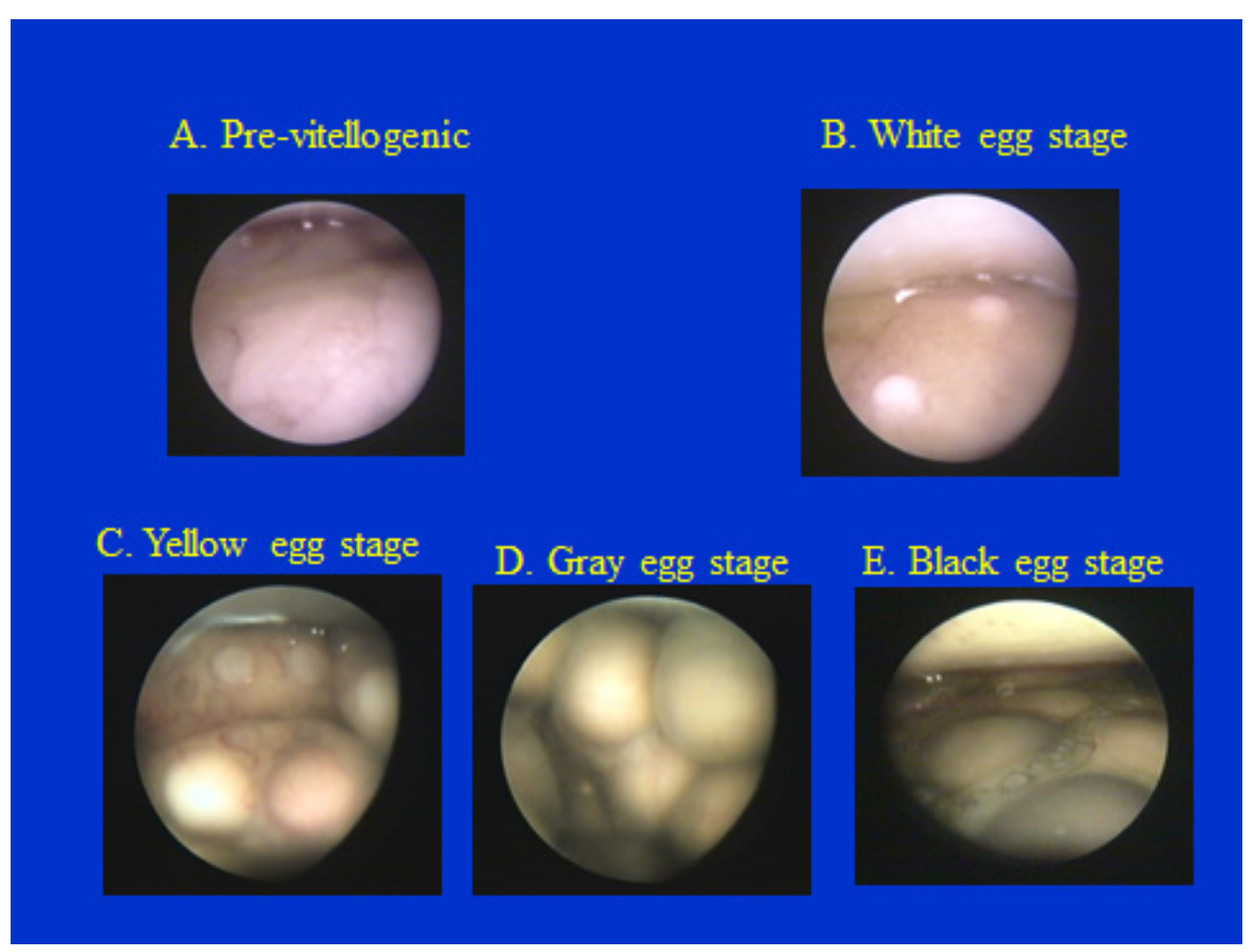

Figure 1. Different stages of oogenesis in the ovary of Russian sturgeon. A - pre-vitellogenesis, B - yellow stage, C - gray stage, D - black stage (caviar).

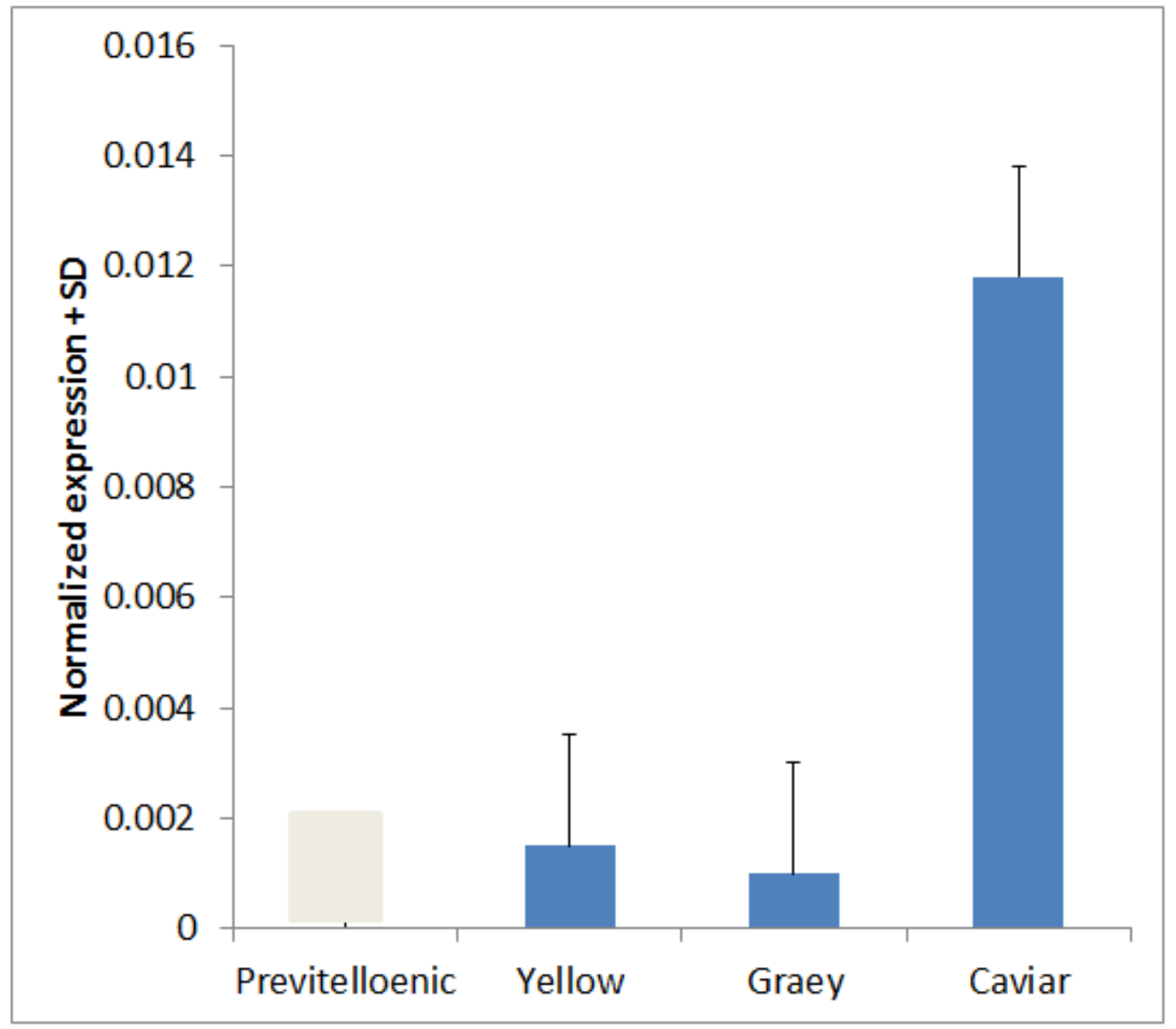

Figure 2. The transcription of IGF-1R in Russian sturgeon ovary at four different stages of oocytes (before vitellogenesis and during vitellogenesis yellow, gray and black) 


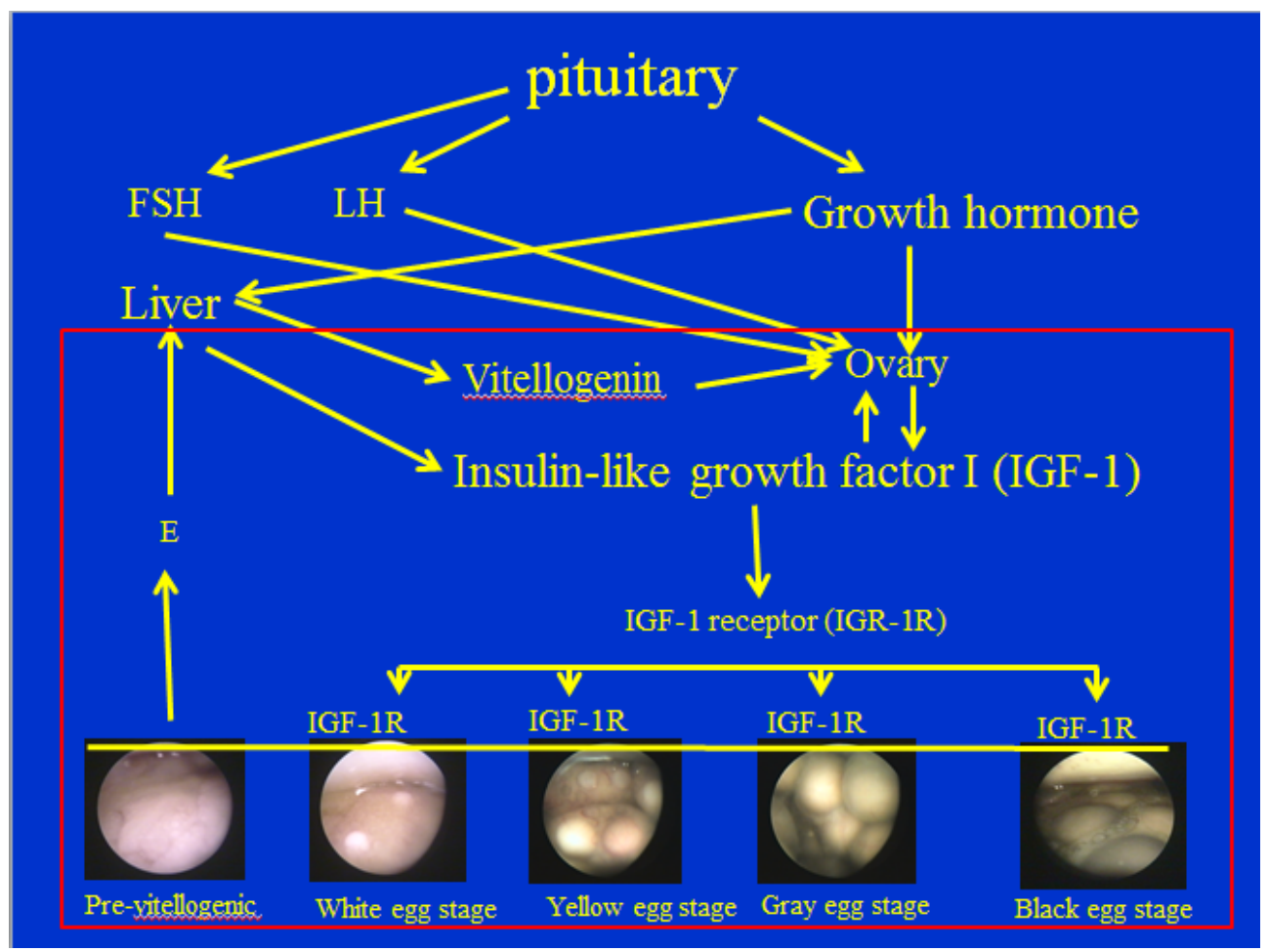

Figure 3. The proposed model for the effect of GH, IGF-1 and IGF-1R involved in the gonad development of Russian sturgeon (Farmer et al.[6]1; Wuertz et al.[21]; Yom Din et al.[24]).

\section{REFERENCES}

[1] Birstein, V.J., Bemis, W.E., Waldman, J.R. (1997) The threatened status of acipenseriformspecies: a summary. Environmental Biology of Fishes 48, 427-436.

[2] Degani, G. (2014) Expression of the growth hormone and insulin-like growth factor genes in the male and female blue gourami (Trichogaster trichopterus) at different temperatures. Journal of Asian Scientific Research 4, 413-427.

[3] Degani, G., Jackson, K., Yom-Din, S., Goldberg, D. (2006) cDNA cloning and mRNA expression of growth hormone in Belontiidae (Anabantoidei suborder) fish. Israel Journal of Aquaculture 58, 124-136.

[4] Degani, G., Tzhori, I., Yom-Din, G., Goldberg, D., Jackson, K. (2003) Growth differences and growth hormone expression in male and female European eels (Anguilla anguilla (L.). Gen. Comp. Endocrinol. 134, 88-93.

[5] Dettlaff, T.A., Ginsburg, A.S., Schmalhausen, O.I. (1993) Sturgeon fishes: developmental biology and aquaculture. New York: Springer Verlag.

[6] Farmer, S.W., Hayashida, T., Papkoff, H., Polenov, A.L. (1981) Characteristics of growth hormone isolated from sturgeon (Acipenser güldenstädti) pituitaries. Endocrinology 108, 377-381.

[7] Hurvitz, A., Degani, G., Goldberg, D., et al. (2004) Cloning of FSH $\beta$, LH $\beta$ and glycoprotein $\alpha$ subunits from the Russian sturgeon (Acipenser gueldenstaedtii), $\beta$ subunits mRNA expression, gonad development and steroid levels in

immature fish. Gen. Comp. Endocrinol. 140, 61-73.

[8] Hurvitz, A., Jackson, K., Degani, G., Levavi-Sivan, B. (2007) Use of endoscopy for gender and ovarian-stage determinations in Russian sturgeon (Acipenser gueldenstaedtii) grown in aquaculture. Aquaculture 270, $158-166$.

[9] Jackson, K., Hurvitz, A., Yom Din, S., et al. (2006) Anatomical, hormonal and histological descriptions of captive Russian sturgeon (Acipenser gueldenstaedtii) with intersex gonads. Gen. Comp. Endocrinol. 148, 359-367.

[10] Levy, G., Degani, G. (2011) Evidence for a reproduction-related function of pituitary adenylate cyclase-activating polypeptide-related peptide (PRP) in an Anabantidae fish. J. Mol. Endo. 46, 1-11.

[11] Livak, K.J., Schmittgen, T.D. (2001) Analysis of relative gene expression data using real-time quantitative PCR and the 2(-Delta Delta C(T)) method. Methods 5 402-408.

[12] Lokman, P.L., George, K.A.N., Divers, S.L., Algie, M., Young, G. (2007) 11-Ketotestosterone and IGF-I increase the size of previtellogenic oocytes from shortfinned eel, Anguilla australis, in vitro. Reproduction 133, 955-967.

[13] Lubzensa, E., Youngb, G., Bobed, J., Cerdàe, J. (2010) Oogenesis in teleosts: how fish eggs are formed. General and Comparative Endocrinology 165, 367-389.

[14] Moriyama, S., Ayson, F.G., Kawauchi, H. (2000) Growth regulation by insulin-like growth factor-I in fish. Biosci Biotechnol Biochem 64,1553-1562.

[15] Muller, P.Y., Janovlak, H., Miserez, A.R., Dobbie, Z. (2002) Processing of gene expression data generated by quantitative real time RT-PCR. Biotechniques 32, 1372-1379. 
[16] Perez-Sanchez, J. (2000) The involvement of growth hormone in growth regulation, energy homeostasis and immune function in the gilthead sea bream (Sparus aurata): a short review. Fish Physiol Biochem 22, 135-144.

[17] Sadler, S.E., Angleson, J.K., Dsouza, M. (2009) IGF-1 receptors in Xenopus laevis ovarian follicle cells support the oocyte maturation response. Biology of Reproduction 82(3), 591-598.

[18] Scott, A.P. (1987) Reproductive endocrinology of fish. In: Chester Jones C., Ingleton P.M. \& Phillips J.C. (eds.), Fundamentals of Comparative Vertebrate Endocrinology. New York: Plenum Press 223-256.

[19] Van Eenennaam, J.P., Doroshov, S.I. (1998) Effect of age and body size on gonadal development of Atlantic sturgeon. $J$. Fish Biol. 53, 624-637.

[20] Vlasenko, A.D., Pavlov, A.V., Sokolov, L.I., Vasil'ev, V.P. (1989) Acipenser gueldenstaedtii Brandt, 1833. In: Holcik, J. (ed.), The Freshwater Fishes of Europe Vol. 1 Part II: General Introduction to Fishes. Acipenseriformes.
AULA-Verlag, Wiesbaden 1.

[21] Wuertz, S., Nitsche, A., Jastroch, M., et al. (2007) The role of the IGF-1 system for vitellogenesis in maturing female starlet, Acipenser ruthenus Linaeus. Gen. Comp. Endocrinol. 150, 140-150.

[22] Yaron, Z., Levavi-Sivan, B. (2011) Endocrine regulation of fish reproduction. In: Farrell A.P., (ed.), Encyclopedia of Fish Physiology: From Genome to Environment 2, 1500-1508.

[23] Yom-Din, S., Hollander-Cohen, J.A., J., Boehm, B., et al. (2016) Gonadotropins in the Russian sturgeon: their role in steroid secretion and the effect of hormonal treatment on their secretion. PLOS ONE. 13, 1-23.

[24] Yom Din, S., Hurvitz, A., Goldberg, D., Jackson, K., Levavi-Sivan, B., Degani, G. (2008) Cloning of Russian sturgeon (Acipenser gueldenstaedtii) growth hormone and insulin-like growth factor 1 and their expression in male and female fish during the first period of growth. Journal of Endocrinological Investigation 31, 201-2010. 